\title{
Age of Natural Menopause Among Jordanian Women and Factors Related to Premature and Early Menopause
}

This article was published in the following Dove Press journal: Risk Management and Healthcare Policy

Mona Bustami
Khalid Z Matalka ${ }^{2}$
Yousef Elyyan ${ }^{3}$
Nagham Hussein ${ }^{4}$
Nour Hussein ${ }^{5}$
Nayef Abu Safieh ${ }^{5}$
Fida Thekrallah ${ }^{3}$
Eyad Mallah (D)
Luay Abu-Qatouseh
Tawfiq Arafat


'Department of Pharmacology and
Biomedical Sciences, Faculty of Pharmacy
and Medical Sciences, University of Petra,
Amman III 96, Jordan; ${ }^{2}$ Matalka's
Scientific Writing, Lexington, MA, USA;
${ }^{3}$ Department of Obstetrics and
Gynecology, Jordan University Hospital,
Amman, Jordan; ${ }^{4}$ Istishari Hospital,
Amman, Jordan; ${ }^{5}$ School of Medicine,
University of Jordan, Amman, Jordan;
${ }^{6}$ Department of Pharmaceutical Medicinal
Chemistry and Pharmacognosy, Faculty of
Pharmacy and Medical Sciences,
University of Petra, Amman II I 96,
Jordan; ${ }^{7}$ Jordan Center for
Pharmaceutical Research, Amman, Jordan

Correspondence: Mona Bustami Email mbustami@uop.edu.jo
Objective: The aim of this study was to assess factors related to the onset of premature/ early natural menopause among Jordanian women.

Methods: A cross-sectional study was conducted in early 2016. Subjects were enrolled based on random drop-off technique to the Obstetrics and Gynecology clinics at the Jordan University Hospital. Women 18 years of age and above were initially eligible to enroll, and women who had surgically induced menopause or specific disease were excluded from the analysis. Relevant data were collected using a questionnaire that included 30 questions. The following variables were collected: socio-demographic, body mass index, chronic conditions, diseases, reproductive characteristics, and health status. Hormone indicators of menopause were tested by measuring estrogen (E2) and follicle-stimulating hormone (FSH) levels. Age at natural menopause (ANM) was self-reported retrospectively and considered an independent variable against BMI, smoking, hormone therapy, and concomitant diseases. Association analysis and multinomial logistic regression were used to examine the associated factors of ANM with adjusted odds ratios (ORs), and their $95 \%$ confidence intervals (CIs) were reported.

Results: A total of 409 women were included in the analysis, aged between 20-75 years. The mean ANM in our sample was $48.5 \pm 5.0$, with $2.7 \%$ of the women experienced premature menopause (ANM <40) and 7.8\% early menopause (ANM 40-44). Within the menopause women $(n=242)$, the percentage of women who had premature menopause was $4.5 \%, 13.6 \%$ with early menopause, and $21.1 \%$ with late menopause (ANM $>52$ ). Smoking was the major risk factor for premature/early menopausal age among Jordanian women with an OR of 2.46 (95\% CI: $1.08-5.59, \mathrm{p}<0.05)$. On the other hand, women with occasional arthritis symptoms and diseases such as hypertension, diabetes, dyslipidemia, and their combination were associated with average (45-52 years) or late menopause ( $>52$ years).

Conclusion: Smoking is the main contributor of premature/early menopause in Jordanian women. Increased awareness and public health policy about the adverse effects of smoking on women's reproductive health are needed.

Keywords: Jordanian women, menopause age, smoking, diseases, socioeconomic variables

\section{Introduction}

Menopause is a natural chapter of the womanhood story. It is considered as a midlife breakthrough reality that is hallmarked by reproductive disability. The median age of natural menopause (ANM) varies according to an ethnic group, genetic, demographic, socioeconomic, dietary, reproductive, and behavior. ${ }^{1-3}$ The international range of ANM being 44.6-55 years, ${ }^{4}$ is quite variable worldwide. For 
instance, it has been reported that the ANM in Europe is 54, 51.4 in North America, and 48.6 in Latin America, and 51.1 in Asia. ${ }^{5}$ This milestone's timing during women's health trajectory is considered critical since it indicates aging is associated with adverse health and psychological effects. Thus, intensive research on women's health wellness regarding early or late ANM aims to reduce the risks of chronic diseases that will reflect public health and global society.

It is recognized that women at ANM are more vulnerable to cardiovascular diseases, ${ }^{5-7}$ osteoporosis, ${ }^{8}$ urogenital inconsistency, estrogen-responsive malignancy, ${ }^{9,10}$ diabetes, vasomotor symptoms, ${ }^{11}$ cognitive problems, ${ }^{12}$ and possibly Alzheimer's disease. ${ }^{13,14}$ Among those, the most critical causes of increased morbidity and mortality are higher risks of myocardial infarction and hypertension. ${ }^{6}$ Early menopause has been reported to be associated with a higher risk of cardiovascular disease allcause mortality, ${ }^{7}$ and osteoporosis, ${ }^{8}$ while late menopause has been associated with an increased risk of breast cancer, ${ }^{9}$ endometrial, ${ }^{10}$ and ovarian cancer. ${ }^{15}$ Hence, identifying the link factors of menopausal age among postmenopausal women, especially those that are amendable, may help prevent morbidity and mortality.

Before ANM occurs, hormone estradiol becomes insufficient. The latter is primarily due to follicle aging leading to ovarian failure or secondary due to granulosa cell apoptosis, $^{16-18}$ or epigenetic factors. ${ }^{19}$ Studies have shown that many other factors affect the ANM, such as the mother's age at menopause, the age at menarche, reproductive life span, use of oral contraceptives, irregular menstrual cycle. ${ }^{20}$ Those factors may contribute alone or in combination to determine the timing of ANM. However, recent data have suggested that more than half of the underlying factors may be non-genetic sources. ${ }^{21}$ Data with respect to smoking, body mass index (BMI), ${ }^{22}$ the number of pregnancies proved to be linked to the timing of ANM. ${ }^{23}$ Those behavioral factors have been reported to accelerate the $\mathrm{ANM},{ }^{17}$ knowing that, globally, the ANM has been increased across populations. ${ }^{24}$

Cessation of menstruation before the age of 40 has been defined as premature menopause in clinical practice. $^{25}$ In comparison, cessation of menstruation before the age of 45 years is defined as early menopause. However, the stage before menopause is referred to as the perimenopausal stage, characterized by irregular menses within the last 12 months or the absence of menstrual bleeding for more than 3 months but less than 12 months.
Symptoms related to menopause transition are quite variable, and several symptoms variations are also reported among different nations. Menopausal transitional symptoms may affect the quality of life with markers of vasomotor symptoms, vaginal dryness, sleep problems, mood changes, and vaginal dryness. ${ }^{26}$ The study of Women's Health Across the Nation (SWAN) has analyzed signs and symptoms of multi-ethnic, multi-race, multi-site study of 14,906 mid-aged women, which has revealed consistency in menopausal symptoms such as hot flushes, night sweats, psychological and psychosomatic symptoms. ${ }^{27}$ Also, recent SWAN revealed a broad window of variations in the age of onset of different menopausal stages within a population but less different among different populations. SWAN's study also investigated specific variations in sexual hormonal profile and menopausal symptoms among different populations indicating that menopause is a trait that can be predicted, de-evolved, and controlled. ${ }^{28}$

To date, few studies were carried out on Jordanian women emphasizing on the severity of menopausal symptoms as an assessment of women's health and needs. ${ }^{29-31}$ In this study, we investigated the actual ages of Jordanian women at different menopausal stages and the implications of environmental factors, specifically smoking and BMI, together with underlining diseases and socioeconomic factors. The study aimed to determine the factors that may play a role in the premature/early ANM among Jordanian women.

\section{Materials and Methods Study Approval and Design}

A cross-sectional design protocol was submitted and approved by the Research Ethics Committee at the Jordan University Hospital (Approval \#38/2015) in early 2016. This study was carried out at the Jordan University Hospital per the Declaration of Helsinki, whereby all subjects have read and signed an informed consent to enroll in the study.

\section{Subjects}

Subjects were selected based on random drop-off technique to the Obstetrics and Gynecology clinics at the Jordan University Hospital. Women 18 years of age and above were initially eligible to enroll. We included younger group of females as a control group for comparison purposes while studying hormone indicators, the vasomotor, 
psychosocial, and physical symptoms in Jordanian women during menopausal transition period and aging.

Four hundred and sixty-eight females were enrolled in the study. Initially, patients were stratified into seven groups according to their age. Each participant answered a questionnaire containing 30 questions with the help of health trained workers. The questions have information about menopause status, menstrual cycle, diseases, uterus, heart, breast conditions, sleep, mood, hot flushes, memory, and socioeconomic variables such as marital status, type of work, salary, and education. Hormone therapy was also included in the questionnaire as a treatment for instance regulating menstrual period or having ovarian cysts. Also, each subject's weight and height were recorded, and body mass index (BMI) was calculated. Out of the 468 subjects, 59 data from women with hysterectomy or oophorectomy before the age of 55, Turner syndrome, systemic lupus erythematosus, and not Jordanians were excluded from the analysis.

\section{Biochemical Tests}

Blood samples were drawn from each participant to assess their estrogen (E2) and follicle-stimulating hormone (FSH). For the females in the premenopausal phase, the blood sample was withdrawn in the early days of the follicular phase. The E2 and FSH were measured on Elecsys 2010. The lower detection limit was $5 \mathrm{pg} / \mathrm{mL}$ and $0.1 \mathrm{mIU} / \mathrm{mL}$ for $\mathrm{E} 2$ and $\mathrm{FSH}$, respectively.

\section{Data Analysis}

Parameters were scored from 1-4 according to the frequency of symptoms where 1 was "not present", and 4 was "always". Overall health was scored from 1-4, where $1,2,3$, and 4 were referred to as excellent, good, average, and poor, respectively. BMI was classified from 1 to 6 , where $1,2,3,4,5,6$ referred to underweight, standard, overweight, obese 1 , obese 2 , and obese $3 .^{32}$

Depending on the skewness score, continuous data were expressed as either the means \pm SD or median (interquartile range), whereas categorical data were reported as percentages. If skewness score is $<2$, the Student's $t$-test was applied for testing between two groups $\mathrm{n} \geq 8$. Besides, in Student's $t$-test the equal variance was assumed unless Levene's test was significant. Similarly, ANOVA for means or the non-parametric Kruskal-Wallis test for medians was used to compare the quantitative variables among groups, when appropriate. For association analysis, data variables were either analyzed by Chi-square analysis using phi (or Cramer's V) and or binary logistic regression. Multinomial logistic regression analysis was applied for a combination of variables to consider the independent relationships of significant covariates with premature/early menopause after adjusting for age and socioeconomic status at the time of the study. The estimated effect was reported by adjusted odds ratios (ORs) with their $95 \%$ confidence intervals (95\% CIs). A p-value of $<0.05$ was considered to be statistically significant. All analyses were performed using SPSS 25 statistical package.

\section{Results}

\section{Characteristics of the Study Population}

The study group consisted of 409 Jordanian women with a mean age of $48.3 \pm 14.9$ years and range from $20-75$ years (Table 1$)$. The majority were overweight to obese $(69.8 \%)$, married or have been married (74.2\%), have a college degree (51.1\%), housewives $(61.3 \%)$, and have an income of less than 500 JD (equivalent to less than USD 700). In addition, almost half of the participants have chronic diseases such as hypertension, diabetes, dyslipidemia, and osteoporosis.

\section{Natural Menopause Ages in Jordanian Women}

The mean ANM in our sample was $48.5 \pm 5.0$, with $2.7 \%$ of the women experienced premature menopause (ANM <40) and 7.8\% early menopause (ANM 40-44) (Table 2). Within the menopause women $(n=242)$, the percentage of women who had premature menopause was $4.5 \%, 13.6 \%$ with early menopause, and $21.1 \%$ with late menopause $(\mathrm{ANM}>52)$ (Figure 1).

\section{Perimenopause and Hormone Levels}

To assess those women who were still having their period but in the perimenopause phase, the FSH level of $>12.5 \mathrm{mIU} / \mathrm{mL}$ was the initial indicator. There were 12 women $(2.93 \%)$ categorized as $<40(n=2), 40-45(n=6), 46-49(n=3),>50$ $(n=1)$ age groups, respectively. Besides, $50 \%$ of the women had E2 less than $12 \mathrm{pg} / \mathrm{mL}$, and more than half of them have an irregular menstrual cycle and hot flushes.

As expected, the FSH level was higher in the perimenopause and menopausal age groups $(\mathrm{p}<0.001)$ than premenopausal women (Table 3). Besides, there was no difference in FSH levels between perimenopause and other menopausal groups ( $\mathrm{p}=0.068)$. On the other hand, E2 levels were lower in the perimenopause and menopausal age groups $(\mathrm{p}<0.001)$ than 
Table I Characteristics of the Study Population

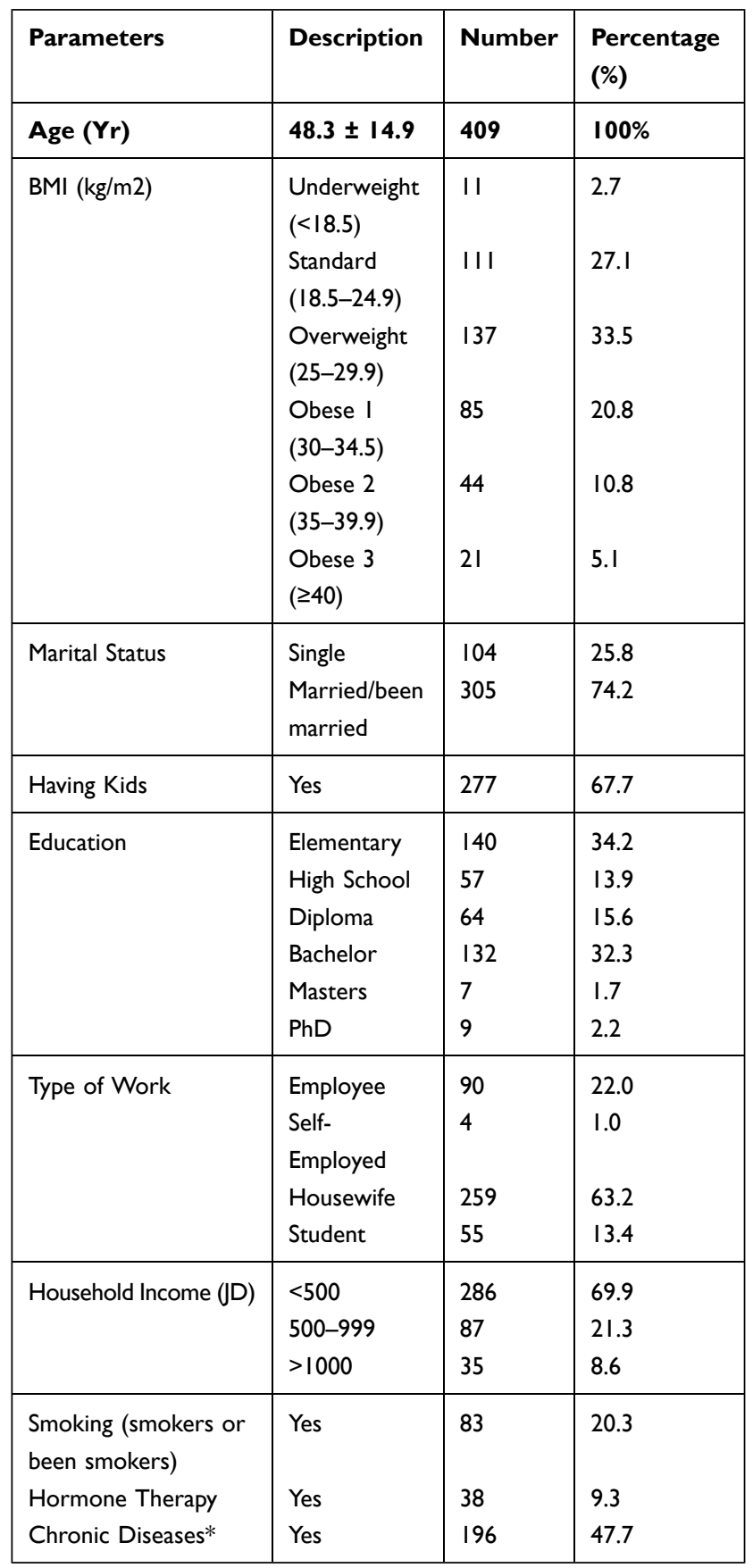

Note: *Mainly hypertension (3I.1\%), dyslipidemia (16.9\%), diabetes (18.8\%), osteoporosis $(12.2 \%)$, ovarian cysts (13\%), uterine fibrosis (13.0\%).

premenopausal women, and there was no difference in E2 levels between perimenopause and other menopausal groups $(\mathrm{p}=0.086)$.

\section{Vasomotor, Psychosocial, and Physical Symptoms}

The mean scores of the frequency of vasomotor, psychosocial, and physical symptoms, and the mean score of
Table 2 Premenopause and Natural Menopause Status in Jordanian Women

\begin{tabular}{|l|l|l|l|}
\hline Groups & Frequency & Percent & Cl 95\% \\
\hline Premature menopause & $\mathrm{II}$ & 2.7 & $1.9-5.6$ \\
$(<40 \mathrm{y})$ & & & \\
Early menopause (40-44 y) & 33 & 8.1 & $5.4-10.8$ \\
Average menopause (45-52 y) & 147 & 35.9 & $28.8-44.1$ \\
Late menopause (>52 y) & $5 \mathrm{I}$ & 12.5 & $9.4-16.0$ \\
Pre-menopause & 167 & 40.8 & $36.3-46.0$ \\
Total & 409 & 100.0 & \\
\hline
\end{tabular}

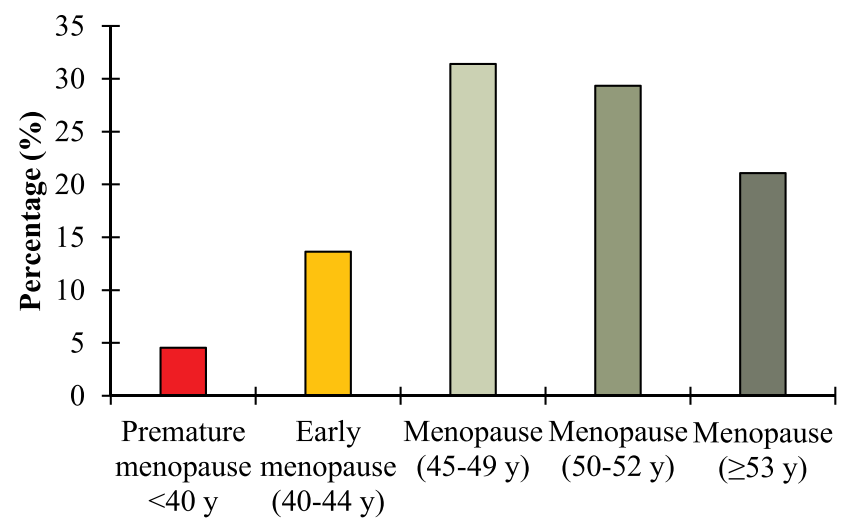

Figure I The percentage distribution of menopause in Jordanian women, according to the cessation of menstruation age onset.

Table $3 \mathrm{FSH}$ and E2 Levels in Premenopausal, Perimenopausal, Menopausal Age Groups of Jordanian Women

\begin{tabular}{|l|l|l|l|l|}
\hline Status & \multicolumn{2}{l|}{ FSH (mIU/mL) } & \multicolumn{2}{l|}{ E2 (pg/mL) } \\
\hline & $\begin{array}{l}\text { Median } \\
\text { (IQR) }\end{array}$ & $\begin{array}{l}\text { CI } \\
95 \%\end{array}$ & $\begin{array}{l}\text { Median } \\
\text { (IQR) }\end{array}$ & CI 95\% \\
\hline Premenopause & $4(4)^{*}$ & $5-6$ & $136(64)^{*}$ & $60-212$ \\
Perimenopause & $33(24)$ & $23-55$ & $20(28)$ & $8-33$ \\
$<40$ & $25(32)$ & $9-42$ & $29(23)$ & $3-55$ \\
$40-44$ & $36(37)$ & $28-45$ & $37(46)$ & $18-56$ \\
$45-49$ & $49(49)$ & $42-56$ & $18(11)$ & $11-25$ \\
$50-52$ & $48(15)$ & $40-55$ & $16(15)$ & $12-21$ \\
$>52$ & $79(13)$ & $35-55$ & $79(13)$ & $-39-196$ \\
\hline
\end{tabular}

Note: ${ }^{*}<0.001$ between premenopausal levels and the other statuses.

overall health of the studied population are presented in Table 4. It is evident that overall health, BMI, arthritis pain, hot flushes and inconsistent urination were significantly higher in the early and regular menopause than in premenopause and perimenopause women. On the other hand, facial hair was significantly less in regular menopause age group. 


\section{Variables Associated with Premature/ Early Menopausal Age Groups}

Several variables that may associate with premature and early menopause in comparison to normal or late menopause age were evaluated. Smoking was associated with premature/early menopause with an OR of 2.46 (95\% CI: $1.08-5.59 ; \mathrm{p}<0.05$ ) (Table 5). Although hormone therapy showed an OR of 2.53, this association was not significant $(p=0.072)$. On the other hand, diseases in general such as hypertension, dyslipidemia, diabetes, heart conditions, and their combinations were significantly associated with normal or later menopausal age women $(\mathrm{p}<0.05)$ (Table 5). Besides, none of the variables, such as BMI, arthritis, osteoporosis, uterine fibrosis, ovarian cysts, having kids, and socioeconomic conditions such as work, marital status, working hours, salary, and education showed an association with either menopausal age.

Although smoking was associated with premature/early menopause and the ANM in smokers (46.7 \pm 6.5$)$ was lower than women who were not smokers $(48.8 \pm 4.6)$, this latter

Table 4 Mean Scores of the Frequency of Vasomotor, Psychosocial, and Physical Symptoms with the Mean Score of Overall Health

\begin{tabular}{|c|c|c|c|c|c|}
\hline Condition & $\begin{array}{l}\text { Premenopause } \\
(n=\mid 55)\end{array}$ & $\begin{array}{l}\text { Perimenopause } \\
(n=\mid 2)\end{array}$ & $\begin{array}{l}\text { Early Menopause } \\
<45 \text { Years } \\
(n=43)\end{array}$ & $\begin{array}{l}\text { Regular Menopause } \\
\geq 45 \text { Years } \\
(n=199)\end{array}$ & $P$ value \\
\hline Age & $33.2 \pm 10.9$ & $45.0 \pm 5.5$ & $53.7 \pm 8.7$ & $58.9 \pm 6.2$ & \\
\hline BMI classification & $2.67 \pm 1.03$ & $3.08 \pm 1.24$ & $3.33 \pm 1.02 *$ & $3.70 \pm 1.15^{*}$ & $<0.001$ \\
\hline Arthritis pain & $1.66 \pm 1.09$ & $1.64 \pm 1.12$ & $2.35 \pm 1.48^{*}$ & $2.48 \pm 1.36 *$ & $<0.001$ \\
\hline Facial Hair & $1.65 \pm 1.03$ & $1.64 \pm 1.12$ & $1.5 I \pm 1.08$ & $1.37 \pm 0.88 *$ & 0.059 \\
\hline Hot flushes & $1.49 \pm 0.89$ & $2.00 \pm 1.4 \mid$ & $1.65 \pm 1.23$ & $2.10 \pm 1.24 *$ & $<0.001$ \\
\hline Loss of Sexual Desire & $1.43 \pm 0.91$ & $1.10 \pm 0.32$ & $1.38 \pm 0.96$ & $1.48 \pm 0.99$ & NS \\
\hline Memory Disturbance & $1.79 \pm 1.03$ & $1.55 \pm 1.04$ & $1.47 \pm 1.03$ & $1.71 \pm 1.16$ & NS \\
\hline Mood swings & $2.02 \pm 1.19$ & $1.64 \pm 1.12$ & $1.53 \pm 1.08$ & $1.82 \pm 1.22$ & NS \\
\hline Saggy Breast & $1.21 \pm 0.68$ & $1.09 \pm 0.30$ & $1.40 \pm 0.95$ & $1.33 \pm 0.83$ & NS \\
\hline Skin Dryness & $1.75 \pm 1.04$ & $1.55 \pm 1.21$ & $1.58 \pm 1.12$ & $1.55 \pm 1.00$ & NS \\
\hline Sleep Disturbance & $1.75 \pm 1.09$ & $1.55 \pm 1.03$ & $1.5 \mathrm{I} \pm 1.05$ & $1.86 \pm 1.21^{*}$ & NS \\
\hline Tachycardia & $1.78 \pm 1.06$ & $1.45 \pm 1.04$ & $1.08 \pm 0.92$ & $1.65 \pm 1.09$ & NS \\
\hline Inconsistent Urination & $1.11 \pm 0.46$ & $1.27 \pm 0.94$ & $1.49 \pm 1.01 *$ & $1.40 \pm 0.85 *$ & $<0.001$ \\
\hline Vaginal Dryness & $1.32 \pm 0.78$ & $1.64 \pm 1.12$ & $1.53 \pm 1.10$ & $1.50 \pm 0.99$ & NS \\
\hline Overall Health ${ }^{T}$ & $|.78 \pm 0.8|$ & $2.27 \pm 0.62 *$ & $2.63 \pm 0.79 *$ & $2.6 I \pm 0.87^{*}$ & $<0.001$ \\
\hline
\end{tabular}

Notes: *The groups that showed statistically significant difference. ${ }^{\mathrm{T}}$ The mean score of overall health.

Table 5 Selected Variables That May Associate with Premature/Early Menopause in Jordanian Women Comparison to Regular/Late Menopause Adjusted with Age Using Logistic Regression Analysis

\begin{tabular}{|l|l|l|l|}
\hline Variables & N (\%) & OR (95 Cl)* & P value \\
\hline Diseases (diseases vs no diseases) & $166(68.6 \%)$ & $0.45(0.22-0.91)$ & $<0.05$ \\
Smoking (smokers or been smokers vs non-smokers) & $34(16.3 \%)$ & $2.46(1.08-5.59)$ & $<0.05$ \\
Hormone therapy (used vs not used) & $21(9.63 \%)$ & $2.53(0.95-6.70)$ & 0.072 \\
Uterus conditions (present vs normal) & $94(38.8 \%)$ & $1.56(0.80-3.25)$ & 0.196 \\
Arthritis symptoms (have or do not have) & $126(52.1 \%)$ & $0.747(0.385-1.446)$ & 0.385 \\
BMI (high vs standard) & $205(84.7 \%)$ & $0.58(0.25-1.37)$ & 0.209 \\
\hline
\end{tabular}

Note: *Reference is $\geq 45$ years menopausal age. 
mean was not statistically significant $(\mathrm{p}=0.074)$. Also, no difference in menopause age between the smoking groups was observed.

\section{Multinomial Analysis}

Adjusting for age and socioeconomic factors, the multinomial analysis showed similar effects with slight variation in the OR, 95\% CI, and p value (Table 6). Smoking was a significant variable for increased odds of women with premature/early menopause (OR 2.6, 95\% CI: 1.06-$6.38, \mathrm{p}<0.05)$. On the other hand, women with occasional arthritis symptoms and diseases such as hypertension, diabetes, dyslipidemia, and their combination were associated with average or late menopause. On the contrary, hormone therapy, higher BMI or uterus conditions were not associated with premature/early menopause.

\section{Discussion}

The current study aimed to understand and comprehend the menopause stages and underlying facts among Jordanian women using a unique wide window age groups ranging from 20 years to 75 years old. The study has explored the changes in the reproductive axis, menstrual cycle, health, environmental factors associated with 409 women's quality of life.

Medical studies failed to predict the exact ANM since it is a gradual and multi-factorial phenomenon. Our findings herein indicated that smoking was the major risk factor for premature/early menopausal age among Jordanian women. A total of $10.8 \%$ of Jordanian women in our sample experienced premature and early menopause, and this percentage was associated with exposure to regular or previous smoking habits. This result was consistent with other previous studies that were not related to Arab women. ${ }^{33-36}$

Although the underlying relationship between smoking and earlier onset of menopause is not well defined, previous studies have hypothesized the irreversible toxic effect of smoking on ovarian function. ${ }^{37,38}$ Nicotine has been found to induce apoptosis of ovarian culture that may reduce ovarian reserve oocytes. ${ }^{37}$ Ruan and Mueck (2015) have demonstrated that smoking drastically affects both endogenous E2 and FSH levels and may cause a decrease or inactivation of the FSH hormone. ${ }^{39}$ These observations agree with the E2 and FSH hormone profile among premature/early menopause in our study. Although we did not account for the intensity, duration, cumulative dose, and timing of smoking with age, it has been shown that smoking and duration of smoking were a strong predictor of ANM. ${ }^{33}$

In the current study, the overall ANM of the tested participants was $48.5 \pm 5.0$. This ANM value is within the range (47.5-49.4) of other studies. ${ }^{29-31}$ However, the later studies did not stress on premature/early menopause age, but more were interested in menopausal symptoms and their implications on Jordanian women's health. In comparison with different populations occupying the neighboring geographical area, El Hajj et al (2020) showed the ANM in Lebanese women was $47.9 \pm 4.5$, which is significantly less $(\mathrm{p}<0.05)$ than ANM in Jordanian women presented in this study. In the former study, more than half of the studied population was smokers, contributing to the significantly lower ANM value. ${ }^{40}$ On the other hand, a study in Saudi Arabia disclosed that the ANM was $48.3 \pm 3$, which was not significantly different than Jordanians, and only $1.8 \%$ were smokers. $^{41}$

Table 6 Multinomial Logistic Regression of Variables Associated with Premature/Early Menopause* with Adjusted or Against Age and Socioeconomic Factors ${ }^{\dagger}$

\begin{tabular}{|l|l|l|l|}
\hline Variables & OR & $\mathbf{9 5 \%} \mathbf{C l}$ & $\mathbf{P}$ value \\
\hline Smoking (Smokers or been smokers vs non-smokers) & 2.60 & $1.06-6.38$ & $<0.05$ \\
Hormone therapy (used vs not used) & 2.65 & $0.911-7.68$ & \\
Arthritis symptoms & & 0.074 \\
$\quad$ Always & 0.16 & $0.35-1.61$ & $0.03-0.84$ \\
Occasional & 0.57 & $0.22-1.46$ & 0.456 \\
BMl (high vs normal) & 0.48 & $0.22-1.02$ & 0.05 \\
Diseases (diseases vs no diseases) & 1.211 & $0.57-2.56$ & 0.056 \\
Uterus condition (present vs normal) & & 0.616 \\
\hline
\end{tabular}

Notes: *Reference is $\geq 45$ years menopausal age. 'Socioeconomic factors are education, type of work, working hours, marital status, and having kids. 
A cross-sectional analysis that was conducted using data obtained from SWAN, Chan, et al (2020) showed that the ANM average of Afro-American, Chinese, Japanese, and Caucasian populations was 52 years and was significantly higher than the Hispanic population (50.8 years). ${ }^{28}$ These values are significantly higher than the ANM in our region/population. On the contrary, an earlier systemic review performed by Palacios et al (2010) have reported ANM for Asians, Latin Americans were similar to our populations but less than those of Europe and North America. ${ }^{5}$ Although meta-analysis has shown variations in ANM among populations may be due partly to the geographical region's difference, lifestyle factors may contribute to almost its similarity. ${ }^{35}$ Our finding revealed that the ANM among Jordanian women was practically identical to women occupying the same geographical region that shares nearly the same lifestyle of living that may have a similar impact on epigenetic factors. ${ }^{19}$

The onset of menopause starts when women transition from the premenopausal or perimenopausal stage. This transitional period is characterized by relative changing levels of serum E2 and FSH. ${ }^{28,42}$ Our results were consistent with other studies where the transitional stage progresses with loss of ovarian follicles presented by reduced E2, causing an increase of FSH. During this period, measuring the hormonal profile of E2 and FSH is necessary to predict the progress of women's menopause. The significance of tracking biomarkers may allow intervening before the onset of any health complications related to ANM. ${ }^{43,44}$

Menopausal symptoms and health complications have a more significant correlation with average or latemenopausal age. ${ }^{45}$ In the present study, chronic diseases were associated with women who had average to late menopause, and the latter was associated with an increase in BMI, arthritis, and overall health. The increase in BMI with age and chronic diseases-related complications is a major concern in Jordanian women, but it is beyond the scope of this article. ${ }^{46}$ However, health complications related to premature/early menopause are substantial to non-fatal cardiovascular diseases before the age of $60 .^{33}$ In the present study, the frequency of heart diseases was $4.7 \%$ in the premature/early menopause group (2 out of 43) compared to $7.0 \%$ (14 out of 199) for women with regular-late menopause. Since the age of premature/early menopause women at the time of this study was only 53.7 \pm 8.7 years compared to $58.9 \pm 6.2$ years for the regular-late menopause group, a concern must be taken. Therefore, more cardiovascular protocols and preventive measures should be implemented for women experiencing premature/early menopause. ${ }^{33}$

Our study has limitations that are worthy of being mentioned. This study was a cross-sectional design, and the ANM was self-reported by women retrospectively; therefore, it depends on the participants to recall their ANM. Studies have shown that remembering ANM has variations that increase with the duration since menopause. ${ }^{47}$ Besides, the study did not show the time of hormone therapy that might have been after the diagnosis of premature or early menopause women. Furthermore, in this study, the sample size was small and may be attributed to a higher percentage of women who had premature/early menopause in relation to total postmenopausal women. ${ }^{33}$ Although our sample size is limited, it's primary strength was the biochemical testing to validate each participant's hormonal status. Besides, the research team involved limited the errors associated with self-reporting or under-reporting.

Although multiple variables were addressed, only smoking showed a correlation with premature/early menopause. This positive correlation should increase smoking awareness in general and among young women and combat smoking through public policies. Furthermore, acknowledging the factors related to early menopause will permit rigorous research. Thus, it is essential to investigate the incorporation of determinant factors influencing menopause age of Jordanian women and the Arab region. Such information will increase the reproductive period and reduce the risk factors associated with cardiovascular morbidity and mortality diseases and lead to disease-less longterm survival.

\section{Acknowledgments}

The authors acknowledge the financial support from the Deanship of Research and Graduate Studies at the University of Petra (Grant Numbers 5-4-2015), Amman, Jordan, and Jordan University hospital to facilitate meeting the participants and collecting samples. A special grateful acknowledgment dedicated to Ms. Suzan Alwawi, University of Petra, for technical assistance and finally to all study participants.

\section{Author Contributions}

All authors made substantial contributions to conception and design, acquisition of data, or analysis and interpretation of 
data; took part in drafting the article or revising it critically for important intellectual content; agreed to submit to the current journal; gave final approval of the version to be published; and agree to be accountable for all aspects of the work.

\section{Disclosure}

The authors declare no conflicts of interest in this work.

\section{References}

1. Parazzini F; Progetto Menopausa Italia Study Group. Determinants of age at menopause in women attending menopause clinics in Italy. Maturitas. 2007;56:280-287. doi:10.1016/j.maturitas.2006.09.003

2. Murphy L, Sievert L, Begum K, et al. Life course effects on age at menopause among Bangladeshi sedentees and migrants to the UK. Am J Hum Biol. 2013;25:83-93.

3. Butts SF, Sammel MD, Greer C, Rebbeck TR, Boorman DW, Freeman EW. Cigarettes, genetic background, and menopausal timing: the presence of single nucleotide polymorphisms in cytochrome P450 genes is associated with increased risk of natural menopause in European-American smokers. Menopause. 2014;21:694-701.

4. Thomas F, Renaud F, Benefice E, Meeus T, Guegan J. International variability of age at menarche and menopause: pattern and main determinant. Hum Biol. 2001;73:271-290.

5. Palacios S, Henderson VW, Siseles N, Tan D, Villaseca P. Age of menopause and impact of climacteric symptoms by geographical region. Climacteric. 2010;13:419-428.

6. Sapre S, Thakur R. Lifestyle and dietary factors determine age at natural menopause. J Midlife Health. 2014;5:3-5.

7. Muka T, Oliver-Williams C, Kunutsor S, et al. Association of age at onset of menopause and time since onset of menopause with cardiovascular outcomes, intermediate vascular traits, and all-cause mortality: a systematic review and meta-analysis. JAMA Cardiol. 2016;1:767-776.

8. Cauley JA, Danielson ME, Greendale GA, et al. Bone resorption and fracture across the menopausal transition: the study of women's health across the nation. Menopause. 2012;19:1200-1207.

9. Li H, Sun X, Miller E, et al. BMI, reproductive factors, and breast cancer molecular subtypes: a case-control study and meta-analysis. J Epidemiol. 2017;27:143-151.

10. Ali AT. Reproductive factors and the risk of endometrial cancer. Int J Gynecol Cancer. 2014;24:384-393. doi:10.1097/ IGC.0000000000000075

11. Thurston RC, Joffe H. Vasomotor symptoms and menopause: findings from the Study of Women's Health across the nation. Obstet Gynecol Clin North Am. 2011;38:489-501. doi:10.1016/j. ogc.2011.05.006

12. Utian WH. Psychosocial and socioeconomic burden of vasomotor symptoms in menopause: a comprehensive review. Health Qual Life Outcomes. 2005;3:47. doi:10.1186/1477-7525-3-47

13. Villa A, Vegeto E, Poletti A, Maggi A. Estrogens, neuroinflammation, and neurodegeneration. Endocr Rev. 2016;37:372-402.

14. Mosconi L, Rahman A, Diaz I, et al. Increased Alzheimer's risk during the menopause transition: a 3-year longitudinal brain imaging study. PLoS One. 2018;13(12):e0207885. doi:10.1371/journal.pone.0207885

15. Tsilidis KK, Allen NE, Key TJ, et al. Oral contraceptive use and reproductive factors and risk of ovarian cancer in the European Prospective Investigation into Cancer and Nutrition. $\mathrm{Br} J$ Cancer. 2011;105:1436-1442. doi:10.1038/bjc.2011.371

16. World Health Organization. Research on the menopause in the 1990s: report of WHO scientific group, Geneva, Switzerland; 1996. Available from: https://apps.who.int/iris/handle/10665/41841. Accessed January 12, 2021.
17. Harlow BL, Signorello LB. Factors associated with early menopause. Maturitas. 2000;35:3-9. doi:10.1016/S0378-5122(00)00092-X

18. Santoro N. The menopausal transition. Am J Med. 2005;118:8S-13S. doi:10.1016/j.amjmed.2005.09.008

19. Hefler LA, Grimm C, Heinze G, et al. Estrogen-metabolizing gene polymorphisms and age at natural menopause in Caucasian women. Hum Reprod. 2005;20:1422-1427. doi:10.1093/humrep/deh848

20. Shadyab AH, Macera CA, Shaffer RA, et al. Ages at menarche and menopause and reproductive lifespan as predictors of exceptional longevity in women: the Women's Health Initiative. Menopause. 2017;24:35-44.

21. Mishra GD, Cooper R, Tom SE, Kuh D. Early life circumstances and their impact on menarche and menopause. Womens Health. 2009;5:175-190.

22. Anderson DJ, Chung HF, Seib CA, et al. Obesity, smoking, and risk of vasomotor menopausal symptoms: a pooled analysis of eight cohort studies. Am J Obstet Gynecol. 2020;222:478.e1-478. e17.

23. Ceylan B, Özerdoğan N. Factors affecting age of onset of menopause and determination of quality of life in menopause. Turk $J$ Obstet Gynecol. 2015;12:43-49.

24. Nichols HB, Trentham-Dietz A, Hampton JM, et al. From menarche to menopause: trends among US Women born from 1912 to $1969 . \mathrm{Am}$ J Epidemiol. 2006;164:1003-1011.

25. Hoek A, Schoemaker J, Drexhage HA. Premature ovarian failure and ovarian autoimmunity. Endocr Rev. 1997;18:107-134.

26. Santoro N, Epperson CN, Mathews SB. Menopausal symptoms and their management. Endocrinol Metab Clin North Am. 2015;44:497-515.

27. Avis NE, Stellato R, Crawford S, et al. Is there a menopausal syndrome? Menopausal status and symptoms across racial/ethnic groups. Soc Sci Med. 2001;52:345-356.

28. Chan S, Gomes A, Singh RS. Is menopause still evolving? Evidence from a longitudinal study of multiethnic populations and its relevance to women's health. BMC Womens Health. 2020;20:74.

29. Al-Qutob R. Menopause-associated problems: types and magnitude. A study in the Ain Al-Basha area, Jordan. $J A d v$ Nurs. 2001;33:613-620.

30. Gharaibeh M, Al-Obeisat S, Hattab J. Severity of menopausal symptoms of Jordanian women. Climacteric. 2010;13:385-394.

31. Jaber RM, Khalifeh SF, Bunni F, Diriye MA. Patterns and severity of menopausal symptoms among Jordanian women. $J$ Women Aging. 2017;29:428-436.

32. James PT, Leach R, Kalamara E, Shayeghi M. The worldwide obesity epidemic. Obes Res. 2001;9:228S-233S.

33. Zhu D, Chung HF, Pandeya N, et al. Relationships between intensity, duration, cumulative dose, and timing of smoking with age at menopause: a pooled analysis of individual data from 17 observational studies. PLoS Med. 2018; 15:e1002704.

34. Mishra GD, Chung HF, Cano A, et al. EMAS position statement: predictors of premature and early natural menopause. Maturitas. 2019;123:82-88.

35. Schoenaker DA, Jackson CA, Rowlands JV, Mishra GD. Socioeconomic position, lifestyle factors and age at natural menopause: a systematic review and meta-analyses of studies across six continents. Int J Epidemiol. 2014;43:1542-1562.

36. Sun L, Tan L, Yang F, et al. Meta-analysis suggests that smoking is associated with an increased risk of early natural menopause. Menopause. 2012;19:126-132.

37. Cheng S, Qin X, Han Z, et al. Nicotine exposure impairs germ cell development in human fetal ovaries cultured in vitro. Aging (Albany NY). 2018;10:1556-1574.

38. Tziomalos K, Charsoulis F. Endocrine effects of tobacco smoking. Clin Endocrinol (Oxf). 2004;61:664-674.

39. Ruan X, Mueck AO. Impact of smoking on estrogenic efficacy. Climacteric. 2015;18:38-46. 
40. El Hajj A, Wardy N, Haidar S, et al. Menopausal symptoms, physical activity level and quality of life of women living in the Mediterranean region. PLoS One. 2020;15:e0230515.

41. AlDughaither A, AlMutairy H, AlAteeq M. Menopausal symptoms and quality of life among Saudi women visiting primary care clinics in Riyadh, Saudi Arabia. Int J Womens Health. 2015;7:645-653.

42. Randolph JF, Zheng $H$, Sowers MR, et al. Change in follicle-stimulating hormone and estradiol across the menopausal transition: effect of age at the final menstrual period. $J$ Clin Endocrinol Metab. 2011;96:746-754.

43. Shieh A, Greendale GA, Cauley JA, Karvonen-Gutierrez C, Crandall CJ, Karlamangla AS. Estradiol and follicle-stimulating hormone as predictors of onset of menopause transition-related bone loss in pre- and perimenopausal women. $J$ Bone Miner Res. 2019;34:2246-2253.
44. El Khoudary SR, Santoro N, Chen HY, et al. Trajectories of estradiol and follicle-stimulating hormone over the menopause transition and early markers of atherosclerosis after menopause. Eur J Prev Cardiol. 2016;23:694-703.

45. Shuster LT, Rhodes DJ, Gostout BS, Grossardt BR, Rocca WA. Premature menopause or early menopause: long-term health consequences. Maturitas. 2010;65:161-166.

46. Al Nsour M, Al Kayyali G, Naffa S. Overweight and obesity among Jordanian women and their social determinants. East Mediterr Health J. 2013;19:1014-1019.

47. Colditz GA, Stampfer MJ, Willett WC, et al. Reproducibility and validity of self-reported menopausal status in a prospective cohort study. Am J Epidemiol. 1987;126:319-325.
Risk Management and Healthcare Policy

\section{Publish your work in this journal}

Risk Management and Healthcare Policy is an international, peerreviewed, open access journal focusing on all aspects of public health, policy, and preventative measures to promote good health and improve morbidity and mortality in the population. The journal welcomes submitted papers covering original research, basic science, clinical \& epidemiological studies, reviews and evaluations,

\section{Dovepress}

guidelines, expert opinion and commentary, case reports and extended reports. The manuscript management system is completely online and includes a very quick and fair peer-review system, which is all easy to use. Visit http://www.dovepress.com/testimonials.php to read real quotes from published authors. 